\title{
Butterfly assemblages from Amazonian flooded forests are not more species-poor than from unflooded forests
}

\author{
Rafael M. Rabelo ${ }^{1,2^{*}}$ and William E. Magnusson ${ }^{1,3}$ \\ ${ }^{1}$ Programa de Pós-Graduação em Ecologia, Instituto Nacional de Pesquisas da Amazônia \\ ${ }^{2}$ Grupo de Pesquisa em Ecologia de Vertebrados Terrestres, Instituto de Desenvolvimento \\ Sustentável Mamirauá \\ ${ }^{3}$ Coordenação de Biodiversidade, Instituto Nacional de Pesquisas da Amazônia
}

\begin{abstract}
The Amazonian flooded and upland forests harbour distinct assemblages of most taxonomic groups. These differences can be mainly attributed to flooding, which may affect directly or indirectly the persistence of species. Here, we compare the density, richness and composition of butterfly assemblages in várzea and terra firme forests, and evaluate whether terrain elevation and flooding can be used to predict the assemblage structure. We found that the total abundance and number of species per plot is higher in várzea than in terra firme forests. Várzea assemblages showed a higher dominance of abundant species than terra firme assemblages, in which low-flying Haeterini butterflies had higher abundance. After standardizing species richness by sample size and/or coverage, species richness estimates for várzea and terra firme forests were similar. There was strong turnover in species composition across várzea and terra firme forests associated with terrain elevation, most likely due to differences in the duration of flooding. Despite a smaller total area, less defined vegetation strata, more frequent disturbances and the younger geological age of floodplain forests, Nymphalid butterfly assemblages are not more species poor there than in unflooded forests.
\end{abstract}

*rmrabelo@gmail.com 


\section{Introduction}

The number and composition of species at a given site is a small subset of the regional 3 species pool because environmental and biotic factors act together or separately to filter

4 species from the regional pool and select the species composition at local scales [1].

5 Vegetation type is the biotic feature most of ten used to represent the spatial distribution of

6 forest-dwelling species, and several forests types can be found in Amazonian landscapes.

Upland terra firme forests account for approximately $83 \%$ of the Amazon basin [2]

8 and are located above the maximum seasonal flood levels of rivers, lakes and large streams.

9 Floodplain várzea forests, on the other hand, are seasonally flooded by nutrient-rich whiteestimated that várzea forests account for 400,000 km² in the Amazon basin [2].

Várzea and terra firme forests harbour distinct assemblages of trees [4], terrestrial mammals [5], bats [6], birds [7] and litter frogs [8]. These differences in species composition are mainly attributed to flooding, which provides a significant barrier to the persistence of all ground-dwelling and understorey species during the high-water season [9], and even for flying species [6,7]. It has been proposed that terra firme has higher species richness than várzea forest because it offers more niches associated with the understorey vegetation [10]. It is expected that upland forests should contain more speciose assemblages of species groups that can persist in flooded and unflooded forests, since they cover a much larger area [11], have more stratified vegetation [12], suffer less frequent disturbances [13] and have greater geological age [14] than flooded forests. On the other hand, floodplain forests tend to have higher species abundance/biomass $[10,15]$ due to the high forest primary productivity, as the white-water seasonal flooding fertilizes várzea soils [16].

Butterflies are strongly associated with specific habitats at all life stages [17]. They are relatively sedentary in the larval stage, but are highly vagile in the adult phase and can have seasonal adaptations (phenological or migratory) to environmental changes. Vegetation gradients represent changes in the availability of food resources and physical conditions of the environment, which directly affect the spatial distribution of Amazonian fruit-feeding butterflies [18-20]. Therefore, environmental changes, such as seasonal flooding, may also filter species from the regional pool, affecting local species richness and composition, although no study has been conducted to test that hypothesis.

This study compares the butterfly assemblages of várzea and terra firme forests in a location in Central Amazonia. Specifically, we aim (i) to test whether the density, richness and composition of butterflies differs between várzea and terra firme forests; (ii) to compare the species-abundance distribution between the two forest types; and (iii) to evaluate whether the assemblage-structure pattern is associated with terrain elevation and flooding. We expected to find a higher butterfly density in várzea forests because they have higher forest primary productivity, which represents higher availability of food 
resources, than terra firme. On the other hand, given that terra firme forests represent a more stable environment and cover a larger area, we expected higher species richness in this forest type. Similarly, we predicted that the butterfly assemblage from várzea forests would have higher dominance of abundant species, and that the species-abundance distribution would be evener in terra firme forests. We also expected to find strong turnover in species composition associated with terrain elevation and flooding.

\section{Materials and Methods}

\section{Study area}

Sampling was undertaken near the confluence of Juruá and Andirá rivers, in Amazonas State, Northern Brazil (S1 Fig). The interfluvium of the junction of these rivers is protected by the Baixo Juruá Extractive Reserve [21]. The Juruá river channel comprises a large floodplain of várzea forests, which are adjacent to unflooded (terra firme) forests.

During the high-water season, várzea forests are flooded by nutrient-rich white-water rivers, with an average annual water-level range of $15 \mathrm{~m}$. Highest river levels occur around May and minima in October [21]. Mean annual temperature and precipitation are around $26{ }^{\circ} \mathrm{C}$ and $2255 \mathrm{~mm}$, respectively, with mean precipitation around $60 \mathrm{~mm}$ during the dry season $[21]$.

\section{Sampling design and data collection}

Sampling was done in five plots located in várzea and nine in terra firme forests (S1 Fig) at the beginning of the low-water season (July 2018). The sampling design followed the RAPELD method as part of a long-term ecological project that aims to compare the distributions of multiple taxa [22]. Plots (sample units) had 250-m long center lines and were uniformly distributed in the landscape, following the elevation contour to minimize variation in soil conditions and its correlates within the transects [23]. Most plots were separated by at least $1 \mathrm{~km}$ from one another, but some terra firme plots were separated by only 500 m due to logistical constraints (S1 Fig).

Butterfly surveys were conducted via active and passive sampling. We placed six equally-spaced butterfly baited traps along the center line of each plot. Traps were hung from tree branches in the forest understorey (1.5-2 m high). We baited the traps with a mixture of sugar-cane juice and bananas fermented for $48 \mathrm{~h}$ [24] and visited them every 24 $\mathrm{h}$ to check for captures and replace the bait. We left the traps active for five consecutive days in each plot. This sampling effort is based on [25], which suggested that it is sufficient to identify ecological responses of understorey fruit-feeding butterfly assemblages.

We also used insect nets to sample low-flying Haeterini species and other Nymphalid species. On each visit to the plots, two researchers with standard 37-cm diameter insect nets actively searched for butterflies during $30 \mathrm{~min}$. All captured individuals were collected for 
species identification and the specimens were deposited in the Entomological Collection of the Mamirauá Institute for Sustainable Development, Tefé, Brazil.

We obtained the elevation data from the digital elevation model (DEM) in the HYDRO1k database developed by the US Geological Survey (http://ta.cr.usgs.gov/HYDRO1K; S1 Fig). We obtained terrain-flooding data from the Synthetic Aperture Radar of the Japonese Earth Resources Satellite - JERS-1 SAR (http://earth.esa.int). JERS-1/SAR images are radar images which, in the Amazon, indicate flooded forests areas by brighter pixels, closed-canopy forests by median brightness, and open water as darker pixels (S1 Fig).

\section{Data analysis}

We compared the total abundance and observed number of species per plot between várzea and terra firme forests with a Kruskal-Wallis test, as the data had a non-normal distribution. We used rarefaction and extrapolation of standardized number of species in order to compare species richness in the two forest types. We standardized the number of species by both number of sampled individuals and sampling coverage, following the recommendations of Chao et al. [26]. Rarefaction and extrapolation were based on sampling coverage in addition to sample size, because standardizing samples by number of individuals usually underestimates species richness of assemblages with more species [27]. We also used the Kolmogorov-Smirnov test to compare the species-abundance curves from the two forest types and sampling methods.

We built a species by site matrix, recording each species (columns) abundance per plot (rows). We standardized the abundances by dividing the number in each matrix cell by the total abundance in the matrix row (plots) to reduce the discrepancy between sites with different numbers of individuals captured. We summarized butterfly species composition by a principal coordinates analysis (PCoA) ordination, based on the Bray-Curtis dissimilarity index. The scores from the first axis derived from this ordination were used to represent the butterfly species composition in each plot. We used a permutational multivariate analysis of variance (PERMANOVA) to evaluate whether the species composition differed between the two forest types. Terrain elevation and flooding were highly correlated (Pearson correlation: $r=-0.96, p<0.01$, S1 Fig). Thus we conducted an analysis of covariance (ANCOVA) to evaluate the effect of elevation on the pattern of assemblage structure, which was represented by first PCoA axis, in each forest type (factor). All analyses were undertaken in the vegan 2.4-4 [28] and iNEXT [29] packages of the R 3.4.4 statistical software [30]. 


\section{Results}

We captured 357 individuals belonging to 56 butterfly species (S1 Table). The most abundant species in várzea forests was Pseudodebis marpessa, and Euptychia mollina was the most abundant in terra firme. Singletons and doubletons were represented by 19 species $(\sim 49 \%)$ in várzea forests and $18(\sim 67 \%)$ in terra firme.

The median number of butterflies counted per plot in várzea forests was 27 (first quartile (Q1) and third quartile (Q3) were 26 and 45, respectively), and was significantly higher than the medium number of butterflies counted in terra firme plots $(\mathrm{Q} 1=5$; median $=9 ; \mathrm{Q} 3=11$; Kruskal-Wallis, $H=6.10, p<0.01$; Fig 1a). The abundance distribution of species also differed between the two forest types (Kolmogorov-Smirnov, baited traps: $D=$ 0.96, $p<0.01$; insect nets: $D=0.67, p<0.01$; both methods: $D=0.79, p<0.01$; Figs $1 \mathrm{c}$ and S2). The várzea assemblage had higher dominance of abundant species ( $8 \%$ of the species made up 50\% of all individuals, S3 Fig) than the terra firme assemblage, which had an evener distribution of species abundance ( $19 \%$ of the species made up $50 \%$ of individuals, S3 Fig).
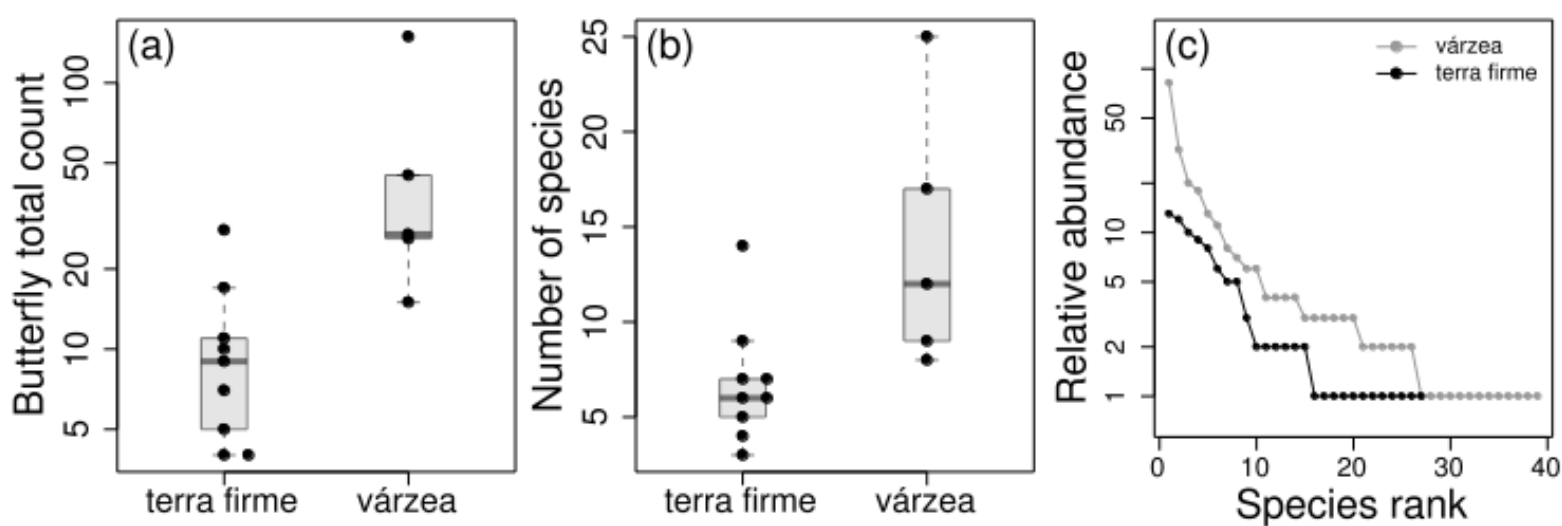

Fig 1. Butterfly counts and number of species in várzea and terra firme forest plots. Difference in butterfly counts (a) and number of species (b) per plot between the two forest types. (c) Assemblage rank-abundance distribution from the two forest types.

The observed number of species per plot was also higher in várzea than in terra firme forests (Kruskal-Wallis, $H=5.80, p<0.05$; Fig $1 \mathrm{~b}$ ), with a median number of 12 species per plot in flooded forests $(\mathrm{Q} 1=9 ; \mathrm{Q} 3=17)$ and $6(\mathrm{Q} 1=5 ; \mathrm{Q} 3=7)$ species per plot in upland forests. However, when the species richness estimate was standardized by sample size and coverage, várzea and terra firme forests showed similar species-richness estimates (Fig 2). Although the terra firme assemblage had a lower estimated sampling completeness (88\%) 
than várzea (95\%; S4 Fig), the rarefaction and extrapolation of species-richness estimates as a function of sample size or coverage showed similar curves (Fig 2).
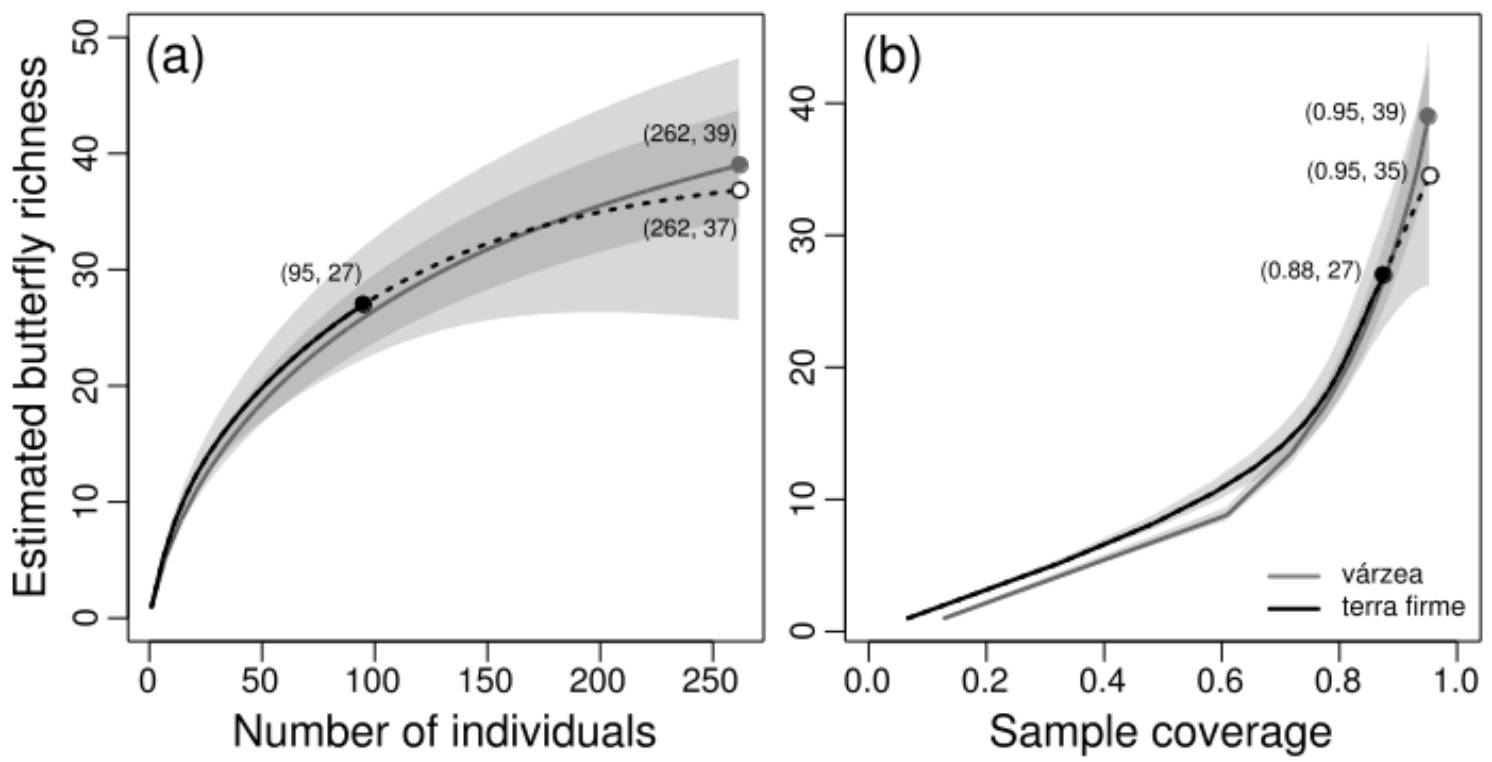

Fig 2. Butterfly richness estimated by rarefaction (solid curves) and extrapolation (dashed curves) based on sample size (a) and completeness (b), with corresponding $95 \%$ confidence intervals (shaded areas). Solid circles indicate the observed species richness and open circles indicate the extrapolated richness in terra firme assemblages based on number of individuals (a) or sample coverage (b). Numbers within parentheses indicate the coordinates of points in both graphs. Although estimated richness in várzea seemed to be slightly higher than terra firme at its maximum sample size (262 individuals in "a") or completeness ( 0.95 of coverage in "b"), the confidence intervals overlap and indicate the there is no statistically significant difference in richness between the two forest types.

The PCoA ordination of plots along the two first axes explained $42 \%$ of the variation in species composition. There was a marked difference between butterfly composition of várzea and terra firme forests (PERMANOVA, $\mathrm{F}=4.23, p<0.01$ ), captured mainly by the first axis (Fig 3a) due to the strong turnover of species composition between forest types (Fig 3b). The várzea species composition was not a nested subset of the terra firme assemblage. The change in species composition was associated with forest types $(\mathrm{F}=19.22$; $p<0.01)$, but without effect of terrain elevation within each forest type $(\mathrm{F}=1.27 ; p=0.29$; Fig 3c). 
(a)

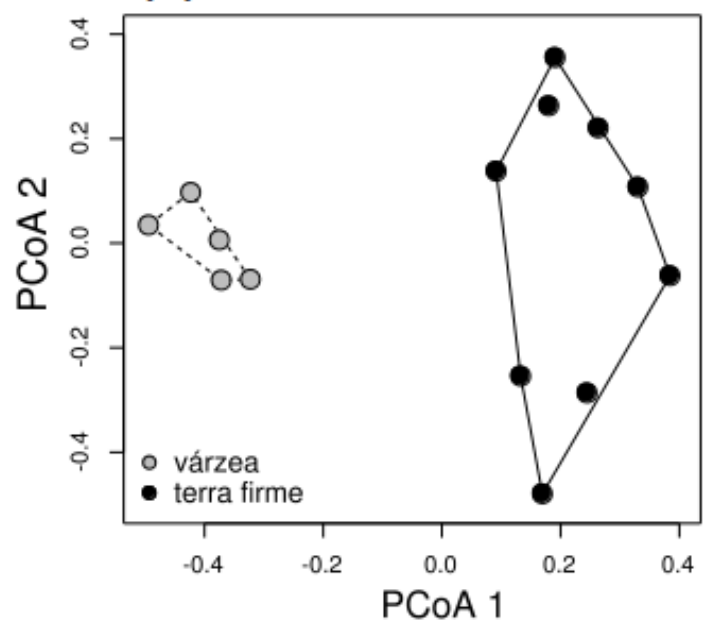

(c)

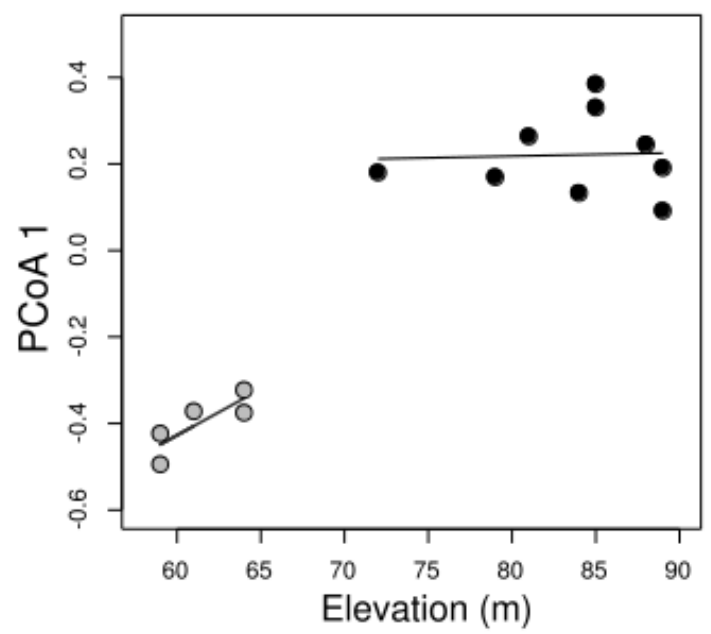

(b)

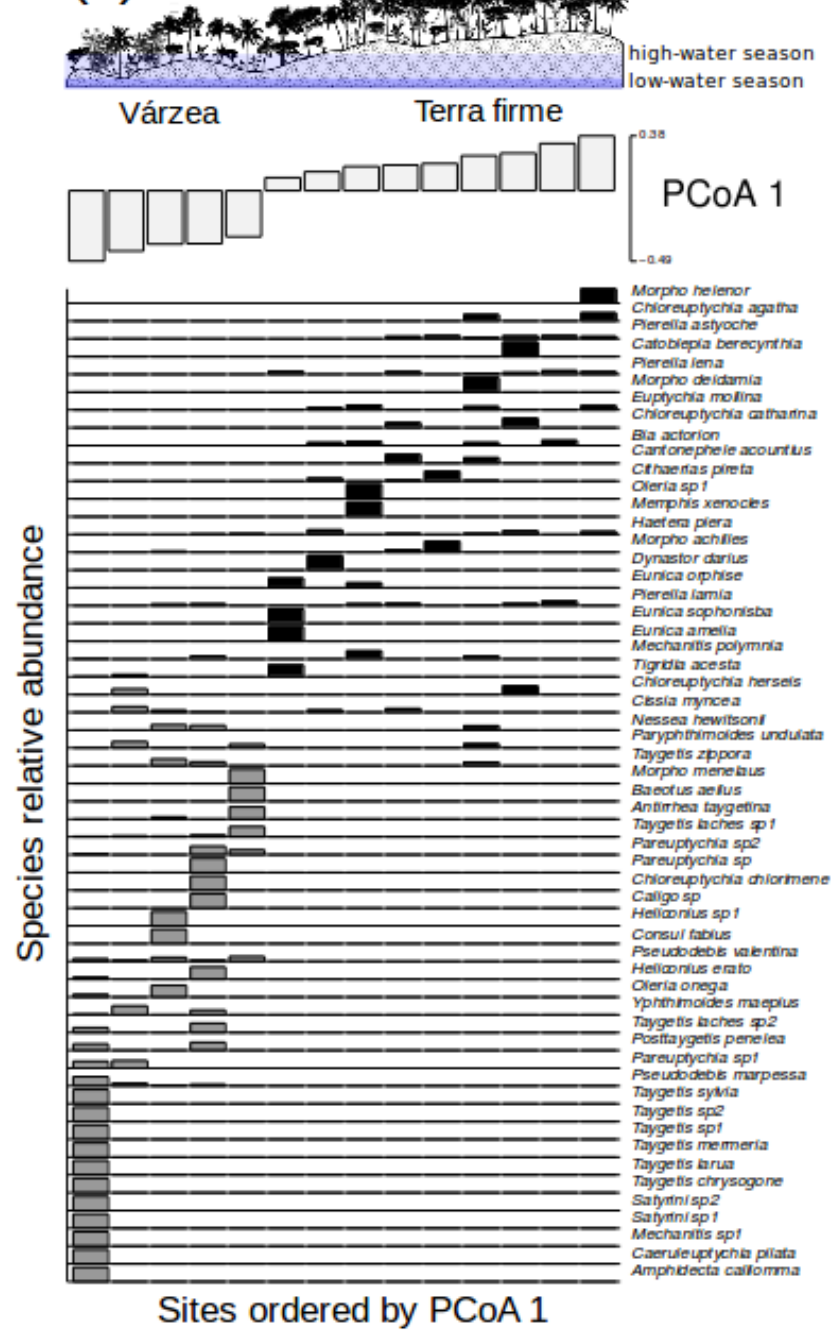

Fig 3. Changes in species composition between várzea and terra firme forests. (a) Similarity in butterfly species composition of plots represented by the distances formed in the two axes derived from the PCoA ordination. Each point in the graph represent a plot located in várzea or terra firme forest and the distance between points represents the similarity of plot in terms of species composition. (b) Distribution of butterflies across sample sites. Sample sites are ordered by the first PCoA axis and bar heights show the relative abundance of butterfly species across várzea (gray) and terra firme (black) plots. (c) Change in species composition (PCoA 1) with elevation within each forest type. 


\section{Discussion}

We found higher butterfly total density in várzea than in terra firme forests, which is the same pattern reported in studies of bats [10] and primates [15]. The higher density of herbivorous, frugivorous and nectarivorous species (such as butterflies, primates and frugivorous bats) in várzea forests is probably due to the higher availability of food resources for these species. Seasonal flooding by white-water rivers provides an extra input of nutrients in várzea soils, which increases forest primary productivity [16]. Bobrowiec et al. [6] found that the abundance of frugivorous bats in várzea forests is even higher during the high-water season. However, for Amazonian fruit-feeding butterflies, adults tend to be more abundant during the early and mid dry season, and less abundant during the wet season [31], when they probably occur in other life stages, such as herbivorous caterpillars.

We found that várzea forests had a higher number of species per plot (i.e., higher species density) than terra firme. This apparent difference in the number of butterfly species between the two forest types occurs because we sampled a much higher number of individuals per plot in várzea forest. Therefore, the difference in the amount of nutrients between the two forest types [16] may also explain the difference in the species density between várzea and terra firme forests. However, the higher number of species per plot found in várzea forests did not result in a higher total butterfly richness in the flooded forest.

The terra firme assemblages had a lower sampling completeness than várzea forest, despite the larger survey effort (nine surveyed plots), and a higher proportion of rare species (singletons and doubletons). When extrapolating the terra firme species richness to the same size/coverage as the várzea's sample, we found that both assemblages showed similar rarefaction and extrapolation curves (Fig 2), indicating that they have similar overall richness.

Poorer assemblages in várzea have been consistently documented for several animal groups $[5,6,15]$, and seasonal inundation is the potential explanation for the lower number of terrestrial and understorey species. However, few studies have attempted to estimate species richness by standardizing the number of species by sample size/coverage prior to undertaking such comparisons (but see [10]). A comparison of bat assemblages between these two forest types, found a higher bat richness in terra firme than in várzea, and the authors suggested that the higher richness occurs because upland forests contain more niches associated with the understorey vegetation [10]. The higher complexity in the terra firme forest structure [16] may also increase the diversity of niches to be occupied by butterflies, explaining the similarity in species richness between the two forest types, despite the lower abundance in the upland forest.

Three butterfly species made up 50\% of all individuals from the várzea assemblages: Pseudodebis marpessa, Oleria onega and P. valentina (S3 Fig). Oviposition of Pseudodebis 
species generally occurs in May-June and its life cycle lasts around 50 days [32], which may explain the high abundance we found during our survey (July). Additionally, Pseudodebis species feed on the bamboo Guadua angustifolia [32], locally known as "taboca", which was highly abundant the várzea plot where we surveyed most Pseudodebis butterflies (R. Rabelo, person. obs.). Oleria are Ithomiinae butteflies that are known to feed on alkaloidrich host plants, which make the adults unpalatable to predators and all species are engaged in mimicry [33,34]. Although adults are unpalatable, it has been suggested that their eggs may be subject to predation or removed from leaves by Ectatomma ants, which are often found on Solanum species [35]. As Ectatomma ants are weak swimmers [36] and do not normally occur in Amazonian seasonally-flooded forests [37], we hypothesize that their absence may favor the high abundance of Oleria in várzea forests.

The rank-abundance distribution was slightly evener in the terra firme assemblage, with five species (19\%) summing more than 50\% of all individuals from the upland assemblage (S3 Fig). Euptychia molina was the most abundant species in terra firme assemblage, followed by three species from the Haeterini tribe. Euptychia butterflies are known for their strong relationship with their host plants, which are among the oldest plant lineages: Selaginellaceae (Lycopsidophyta) and Neckeraceae (Bryophyta) [38,39]. These plant lineages are often obligate terrestrial (Selaginella) and do not occur in floodplain forests [40,41], which may be the reason why E. molina was abundant and restricted to terra firme.

The evener rank-abundance distribution in terra firme forests was mainly caused by the Haeterini butterflies, which tended to be more abundant in this forest type (S1 Table). Three of five Haeterini species were restricted to this forest type (Cithaerias pireta, Pierella astyoche and $P$. lena, Fig 2b). Haeterini butterflies are low-flying ground-dwelling species that feed mainly on rotting fruits and other decaying material on the forest floor [42], and adults can be abundant throughout the year [43]. The host plants for these species are Spathiphyllum sp. for Haetera butterflies [44], Philodendron sp. for Cithaerias butterflies [45] and mainly species from Heliconiaceae and Maranthaceae for Pierella butterflies [38]. Spathiphyllum and Phylodendron species do not occur in várzea forests, and terrestrial species of Heliconiaceae and Maranthaceae may occur in inundated forests, although they are not usually common [40]. Therefore, the seasonal flooding of várzea forests may explain the higher abundance and constrained distribution of Haterini butterflies and their host plants to terra firme forests.

We found a pronounced difference in butterfly species composition between várzea and terra firme forests. The strong turnover of species across forest types was captured by the first PCoA axis. We have discussed some examples of how várzea flooding can affect butterflies and their host plants distribution through increased soil fertility and, consequently, forest primary productivity [16], which results in differences in resources availability - soil nutrients that are resources for host plants, which in turn are resources 
for butterflies. Also biotic constraints due to interaction with predators (e.g., Ectatomma ants that prey upon Oleria eggs and their host plants [35]); and flooding per se, which constrains the distribution of low-flying Haeterini butterflies (and several host plant species) to terra firme forests. Therefore, the results of this study suggest that environmental and biotic filters override the effects of vegetation stratification and effects of source area on differences in the composition of butterfly assemblages in flooded and unflooded Amazonian sites at local scales.

\section{Acknowledgements}

This research was funded by the Instituto de Desenvolvimento Sustentável Mamirauá (IDSM-OS/MCTI) and by the Gordon and Betty Moore Foundation. We thank the logistical support from Instituto de Desenvolvimento Sustentável Mamirauá and from Program for Biodiversity Research (PPBio) and the National Institute for Amazonian Biodiversity (INCT-CENBAM; FAPEAM/FDB/INPA, \#003/2012; and CNPq, \#573721/2008-4, \#722069/2009). Butterfly specimens were collected under permisson SISBIO 57444. We thank Iury Valente e Geanne Pereira from Departamento de Mudanças Climáticas e Unidades de Conservação (DEMUC) for providing butterfly sampling equipment and João Valsecchi for insightful contributions in the early ideas of this work. We also thank the Cumaru village for their cordial reception.

\section{References}

1. Hubbell SP. Neutral theory in community ecology and the hypothesis of functional equivalence. Funct Ecol. 2005; 19: 166-172.

2. Melack JM, Hess LL. Remote sensing of the distribution and extent of wetlands in the Amazon basin. In: Junk WJ, Piedade MTF, Wittmann F, Schöngart J, Parolin P, editors. Amazonian floodplain forests: ecophysiology, biodiversity and sustainable development. New York: Springer; 2010. pp. 43-59.

3. Junk WJ, Piedade MTF, Schöngart J, Wittmann F. A classification of major natural habitats of Amazonian white-water river floodplains. Wetlands Ecol Manage. 2012; 20: 461-475. doi:10.1007/s11273-012-9268-0

4. Wittmann F, Junk WJ, Piedade MTF. The várzea forests in Amazonia: flooding and the highly dynamic geomorphology interact with natural forest succession. For Ecol Manage. 2004; 196: 199-212.

5. Alvarenga GC, Ramalho EE, Baccaro FB, Rocha DG, Ferreira-Ferreira J, Dineli Bobrowiec PE. Spatial patterns of medium and large size mammal assemblages in várzea and terra firme forests, Central Amazonia, Brazil. PLoS One. 2018; 13:0198120. 
6. Bobrowiec PED, Rosa L do S, Gazarini J, Haugaasen T. Phyllostomid bat assemblage structure in Amazonian flooded and unflooded forests. Biotropica. 2014; 46: 312-321.

7. Beja P, Santos CD, Santana J, Pereira MJ, Marques JT, Queiroz HL, et al. Seasonal patterns of spatial variation in understory bird assemblages across a mosaic of flooded and unflooded Amazonian forests. Biodivers Conserv. 2010; 19: 129-152.

8. Gascon C. Amphibian litter fauna and river barriers in flooded and non-flooded Amazonian rain forest. Biotropica. 1996; 28: 136-140.

9. Haugaasen T, Peres CA. Mammal assemblage structure in Amazonian flooded and unflooded forests. J Trop Ecol. 2005; 21: 133-145.

10. Pereira MJR, Marques JT, Santana J, Santos CD, Valsecchi J, Queiroz HL, et al. Structuring of Amazonian bat assemblages: the roles of flooding patterns and floodwater nutrient load. J Anim Ecol. 2009; 78: 1163-1171.

11. MacArthur RH, Wilson EO. The theory of island biogeography. Princeton: Princeton University Press; 1967.

12. MacArthur RH, MacArthur JW. On bird species diversity. Ecology. 1961; 42: 594-598.

13. Connell JH. Diversity in Tropical Rain Forests and Coral Reefs Joseph. Science (80- ). 1978; 199: 1302-1310.

14. Ruokolainen K, Moulatlet GM, Zuquim G, Hoorn C, Tuomisto H. River network rearrangements in Amazonia shake biogeography and civil security; 2018. Preprint. Available from: doi:10.20944/preprints201809.0168.v1. Cited 5 March 2019.

15. Haugaasen T, Peres CA. Primate assemblage structure in Amazonian flooded and unflooded forests. Am J Primatol. 2005; 67: 243-258.

16. Haugaasen T, Peres CA. Floristic, edaphic and structural characteristics of flooded and unflooded forests in the lower Rio Purús region of central Amazonia, Brazil. Acta Amaz. 2006; 36: 25-36.

17. Freitas AV., Leal IR, Uehara-Prado M, Iannuzzi L. Insetos como indicadores de conservação da paisagem. Biologia da Conservação e Manejo da Vida Silvestre. 2006. pp. 357-384.

18. Graça MB, Morais JW, Franklin E, Pequeno PACL, Souza JLP, Bueno AS. Combining taxonomic and functional approaches to unravel the spatial distribution of an Amazonian butterfly community. Environ Entomoly. 2015; 45: 301-309.

19. Graça MB, Pequeno PACL, Franklin E, Souza JLP, Morais JW. Taxonomic, functional, and phylogenetic perspectives on butterfly spatial assembly in northern Amazonia. Ecol Entomol. 2017; 42: 816-826.

20. Ribeiro DB, Freitas AVL. The effect of reduced-impact logging on fruit-feeding butterflies in Central Amazon, Brazil. J Insect Conserv. 2012; 16: 733-744. 
21. ICMBio. Plano de Manejo - Reserva Extrativista do Baixo Juruá. Tefe: Instituto Chico Mendes de Conservação da Biodiversidade - ICMBio / Ministério do Meio Ambiente; 2009.

22. Magnusson WE, Lima AP, Luizão R, Luizão F, Costa FRC, Castilho CV, et al. RAPELD: a modification of the Gentry method for biodiversity surveys in long-term ecological research sites. Biota Neotrop. 2005; 5: 21-26.

23. Costa FRC, Magnusson WE. The need for large-scale, integrated studies of biodiversity - the experience of the Program for Biodiversity Research in Brazilian Amazonia. Nat e Conserv. 2010; 8: 3-12.

24. Freitas AVL, Iserhard CA, Santos JP, Carreira JYO, Ribeiro DB, Melo DHA, et al. Studies with butterfly bait traps: an overview. Rev Colomb Entomol. 2014; 40: 203212.

25. Graça MB, Souza JLP, Franklin E, Morais JW, Pequeno PACL. Sampling effort and common species: optimizing surveys of understorey fruit-feeding butterflies in the Central Amazon. Ecol Indic. 2017; 73: 181-188.

26. Chao A, Gotelli NJ, Hsieh TC, Sander EL, Ma KH, Colwell RK, et al. Rarefaction and extrapolation with Hill numbers: a framework for sampling and estimation in species diversity studies. Ecol Monogr. 2014; 84: 45-67.

27. Chao A, Jost L. Coverage-based rarefaction and extrapolation: standardizing samples by completeness rather than size. Ecology. 2012; 93: 2533-2547.

28. Oksanen AJ, Blanchet FG, Kindt R, Legendre P, Minchin PR, Hara RBO, et al. vegan: Community Ecology Package. R package version 2.0-10; 2013.

29. Hsieh TC, Ma KH, Chao A. iNEXT: an R package for rarefaction and extrapolation of species diversity (Hill numbers). Methods Ecol Evol. 2016; 7: 1451-1456.

30. R Development Core Team. R: A language and environment for statistical computing. Vienna, Austria: R Foundation for Statistical Computing; 2018.

31. Barlow J, Overal WL, Araujo IS, Gardner TA, Peres CA. The value of primary, secondary and plantation forests for fruit-feeding butterflies in the Brazilian Amazon. J Appl Ecol. 2007; 44: 1001-1012.

32. Murray DL. Systematics of Neotropical satyrine butterflies (Nymphalidae: Satyrinae: Euptychiina) based on larval morphology and DNA sequence data and the evolution of life history traits. Louisiana State University. 2001.

33. Beccaloni GW. Ecology, natural history and behaviour of Ithomiine butterflis and their mimics in Ecuador (LEPIDOPTERA: Nymphalidae: Ithomiinae). Trop Lepid. 1997; 8: 103-124. 
34. Brown Jr KS. Chemistry at the Solanaceae/Ithomiinae interface. Ann Missouri Bot Gard. 1987; 74: 359-397.

35. Gallusser SA. Biology, Behaviour and Taxonomy of two Oleria onega subspecies (Ithomiinae, Nymphalidae, Lepidoptera) in north-eastern Peru. Université de Neuchâtel. 2002.

36. Yanoviak SP, Frederick DN. Water surface locomotion in tropical canopy ants. J Exp Biol. 2014; 217: 2163-2170.

37. Wilson EO. The arboreal ant fauna of Peruvian Amazon forests: a first assessment. Biotropica. 1987; 19: 245-251.

38. DeVries PJ. Hostplants records and natural history notes on Costa Rican butterflies (Papilionidae, Pieridae \& Nymphlidae). J Res Lepid. 1985; 24: 290-333.

39. Hamm CA, Fordyce JA. Selaginella and the Satyr: Euptychia westwoodi (Lepidoptera: Nymphalidae) oviposition preference and larval performance. J Insect Sci. 2016; 16: 14.

40. Junk WJ, Piedade MTF. Herbaceous plants of the Amazon floodplain near Manaus: species diversity and adaptations to the flood pulse. Amazoniana. 1993; 7: 467-484.

41. Poulsen AD, Balslev H. Abundance and cover of ground herbs in an Amazonian rain forest. J Veg Sci. 1991; 2: 315-322.

42. Alexander LG, DeVries PJ. Variation in capture height and trap persistence among three Costa Rican understorey butterfly species. J Trop Ecol. 2012; 28: 585-589.

43. Devries PJ, Alexander LG, Chacon IA, Fordyce JA. Similarity and difference among rainforest fruit-feeding butterfly communities in Central and South America. J Anim Ecol. 2012; 81: 472-482.

44. Constantino LM. Notes on Haetera from Colombia, with description of the immature stages of Haetera piera (Lepidoptera: Nymphalidae: Satyrinae). Trop Lepid. 1993; 4: $13-15$.

45. Murillo-Hiller LR. Early stages and natural history of Cithaerias p. pireta (Satyrinae) from Costa Rica. J Lepid Soc. 2009; 63: 169-172. 


\section{Supporting Information}

S1 Fig. Distribution of sample plots in várzea and terra firme forests. (a) Terrain elevation and (b) flooded areas. (c) Correlation between elevation and flooding at sample plot locations.

S1 Table. Abundance of Nymphalidae butterflies collected in 14 plots (five in várzea and nine in terra firme forests) in Baixo-Juruá Extractive Reserve, Amazonas State, Brazil.

S2 Fig. Species-abundance distribution of butterfly species in várzea and terra firme forests sampled with baited traps (left) and insect nets (right). In both sampling methods, the rank-abundance curves of species for different habitats were found to come from different distributions (Kolmogorov-Smirnov, baited traps: $D=0.96, p<0.01$; insect nets: $D=0.67, p<0.01)$.

S3 Fig. Rank-abundance distribution of butterfly species in várzea and terra firme forests.

S4 Fig. Plot of sample coverage for rarefied samples (solid line) and extrapolated samples (dashed line) as a function of sample size for butterfly samples from várzea and terra firme forests, with 95\% confidence intervals (shaded areas). Observed samples are denoted by filled circles. Each of the two curves was extrapolated up to double its observed sample size. The numbers in parentheses are the sample size and the estimated sample coverage for each reference sample. Unfilled circles represent the number of individuals to be sampled from each assemblage when sample coverage is 0.954 (i.e., the sample coverage at double the observed sample size for the terra firme assemblages). 